\title{
An Acoustic Analysis of Indonesian Formant Using Visartico
}

\author{
Ichwan Suyudi, Debyo Saptono \\ Universitas Gunadarma, Jakarta, Indonesia \\ ichwan@staff.gunadarma.ac.id, debyosap@yahoo.com
}

\begin{abstract}
The aims of the research are to design an application of Indonesian phonetic, that is a vocal tract animation and to test this application on the Indonesian non-native speaker. This research is indicated to the experiment of Indonesian phonological description by controlled and measured phonetic experiments. Through the production analysis on native and nonnative Indonesian informants, it is found about the uses of Indonesian phonetic application. The implication of the study is, perceptively, the formant measurement is difficult to do, but by using Visartico (Ouni, 2012) application, formant measurement is successful to do and it has gained accurate value.
\end{abstract}

Keywords : Visartico, Indonesian formant, native, non-native Indonesian.

\section{INTRODUCTION}

Indonesian language nowadays has been learned by at least 72 countries in the world. Even in its development, Indonesian language has become a center of study at universities in the world. It proves that Indonesian language is one of the languages enthused by foreigners. Many people who want to learn Indonesian have a problem with the lacks of the means of phonetics learning and spelling related to the articulation.

This learning program is important to create with the aim for the development of pronunciation and phonetics articulation to BIPA. BIPA is an organization especially for foreigners who are interested in learning Indonesian for many purposes, such as for school, business, work and many others. Indonesian is more easily introduced to them through a phonetic dictionary or articulatory phonetic tools. Indonesian, for foreign speakers, is quite complicated because they have to take a note all the characteristics of speech or a set of statement heard and recognized as precisely as possible. The higher skill of the speaker, it will be closer to mastering the pronunciation (Read, 2002). Through ordinary hearing, all sounds cannot be distinguished objectively.

The aims of this research are to design an Indonesian phonetic application, a vocal tract animation and to test this application on the Indonesian non-native speaker. Therefore the researcher designs an application containing video of the pronunciation of Indonesian phonemes; flash animation phonemes; and the examples of the pronunciation of Indonesian word with the animated articulation through Visartico (Ouni, 2012).

\section{METHODS}

2.1 Technique of data collection

This research consists of two experiments: (1) experiment of production that is by recording the informant reading a set of Indonesian word and (2) perceptual experiment, where the same informant is asked to identify sounds like vowels as one of six vowels in Indonesian.

Regarding the stability of the prosody, all stimulants are put into remain word, vowels which are in the words, the words are given 5 times to each informant in the same random sequence. All informants are asked to read all the words with the same sounds. All instructions are given in Indonesian. The researcher will only show the next word when the informant has read the previous word correctly.

\subsection{Technique of data analysis}

The quality of vowels is mainly determined by center frequencies of the formants, which in this case, the group overtone adjoining reinforced by the resonance of the vocal tract. The center frequency of the first five formants from each part is measured by Linear Predictive Coding (LPC analysis) (Harrington, 1999) and determined the Mean in each vocal. The next analysis is the formant frequencies of the first three formants (F1, F2) (Zanten, 1989). To analysis the data using articulatory phonetic analysis, it is designed a learning model Visartico (Ouni, 2012). The devices used to run this application minimally using a browser that supports HTML version 5.

Minimum Hardware Requirements:

Processor: Intel® Core ${ }^{\mathrm{TM}} \mathrm{i} 3-3217 \mathrm{U} @ 1.80 \mathrm{GHz}, \mathrm{VGA}$

Minimal resolution: $1024 \times 768$

Memory: 4 GB, Hardisk : 500 GB

Software: system operation Windows 7 32-bit, Browser Google Chrome or Mozilla Firefox (support HTML version 5)

\section{RESULT DISCUSSION}

Based on the design of the application that has been made, it is explained that all modules have a homepage, page view vowels, page view of selecting vowels, page view of diphthongs, page view of selecting diphthongs, page view of consonants, page view of selecting consonants. On the screen of the homepage, there are menu options to home, vowels, diphthongs, and consonants. And if you choose option vowels, then the vowels will appear. Figure 1 displays the page of vowels. 


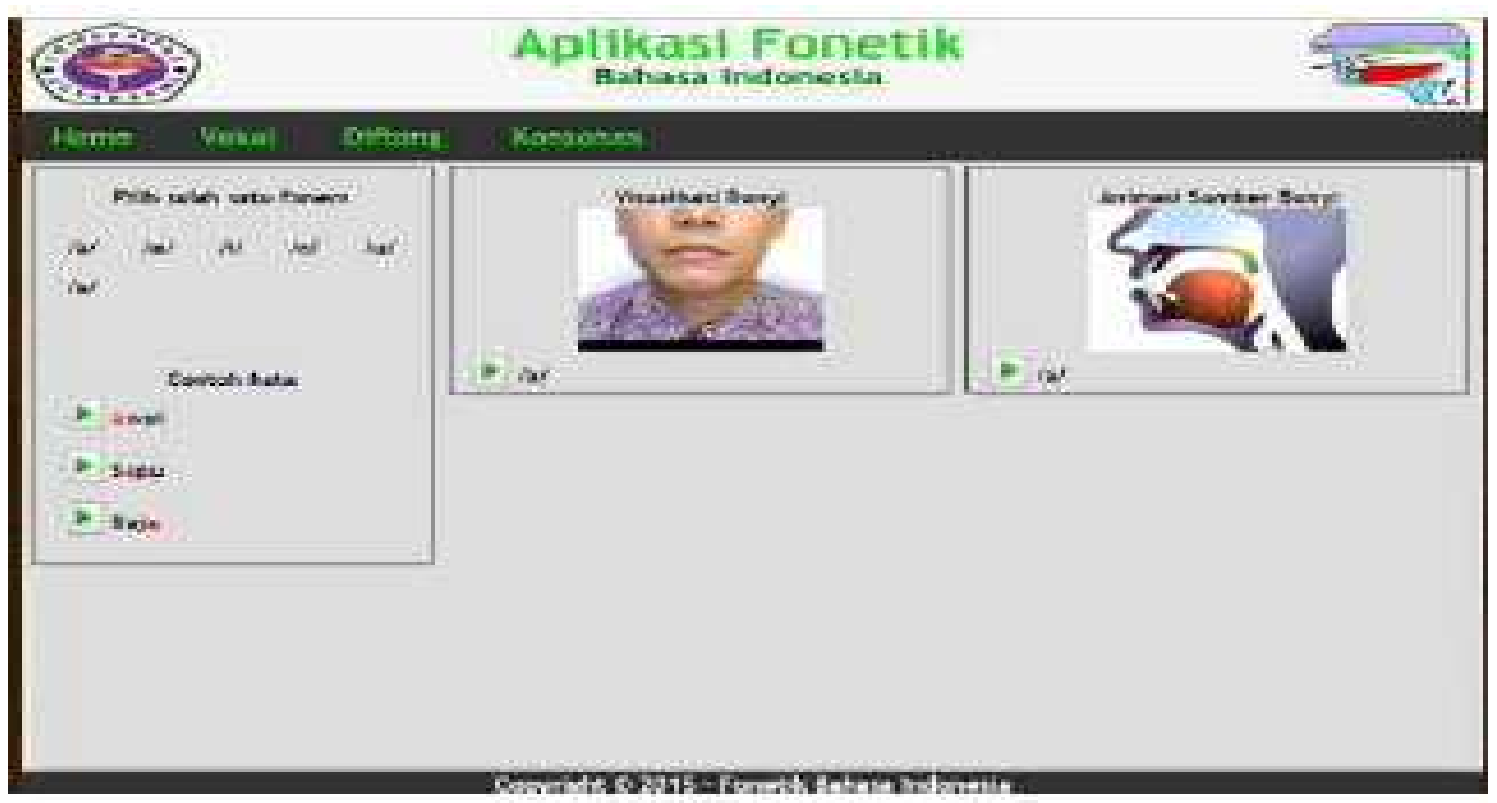

Figure 1. Page of vowels

Page of vowels displays vowels options, namely a, i, o, u and ə. Users can find them if they click 'the vowels' which are in menu bar. This page contains vowels a, i, o, u, and ə. If one phoneme is clicked, it will display a page of sound visualization, sound source animation and examples of word. On the page of sound visualization and source sound animation, there is a 'play' button. If user clicks on each video, then the video will be playing. Then if user chooses one of the listed-words and clicks the 'play' button, it will show an animated word and played directly.

Page of diphthong displays the options of diphthongs au, ai, and oi. Users can find it when they click the 'diphthongs' button which is in the menu bar. If user chooses diphthongs, there will be lists of diphthongs (au, ai and oi). If one of the diphthongs is clicked, it will display the page of sound visualization, sound source animation, and examples of the word. On the page of sound visualization and source sound animation, there is a 'play' button. Then if user chooses one of the listed-words and clicks the 'play' button, it will show an animated word and played directly. Figure 2 displays the page of diphthong.

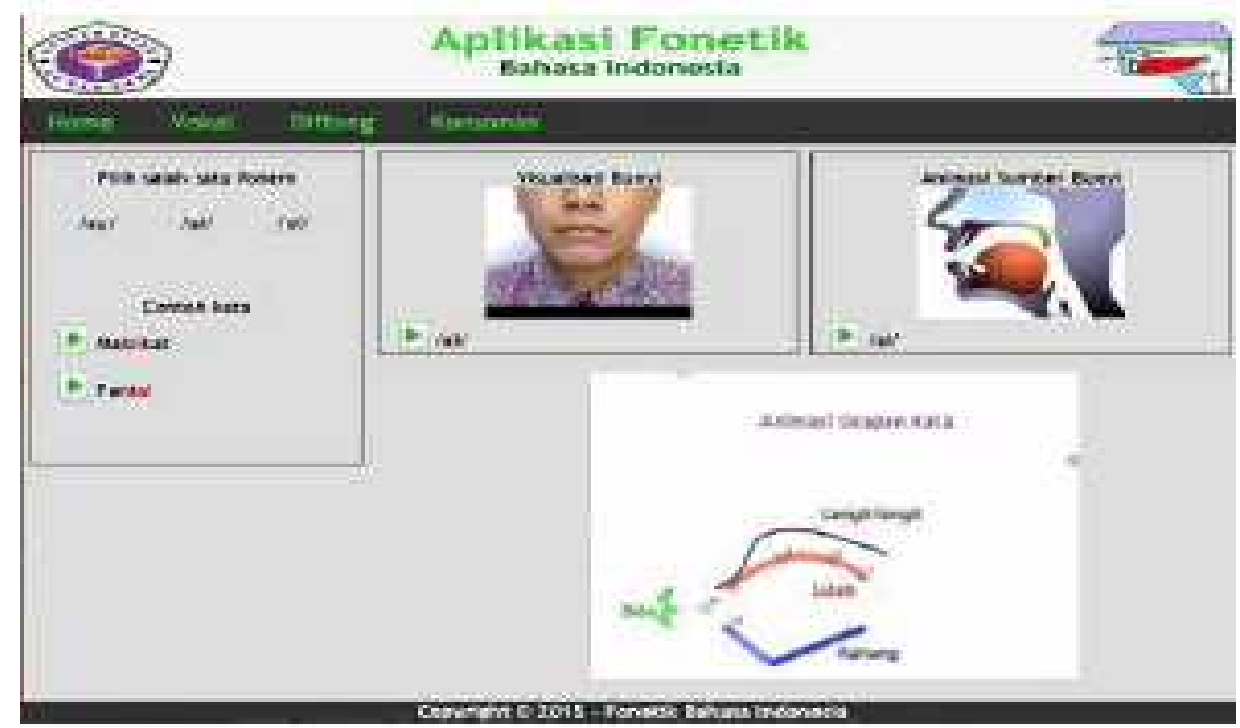

Figure 2. Page of diphthong 
Figure 2, Cont.

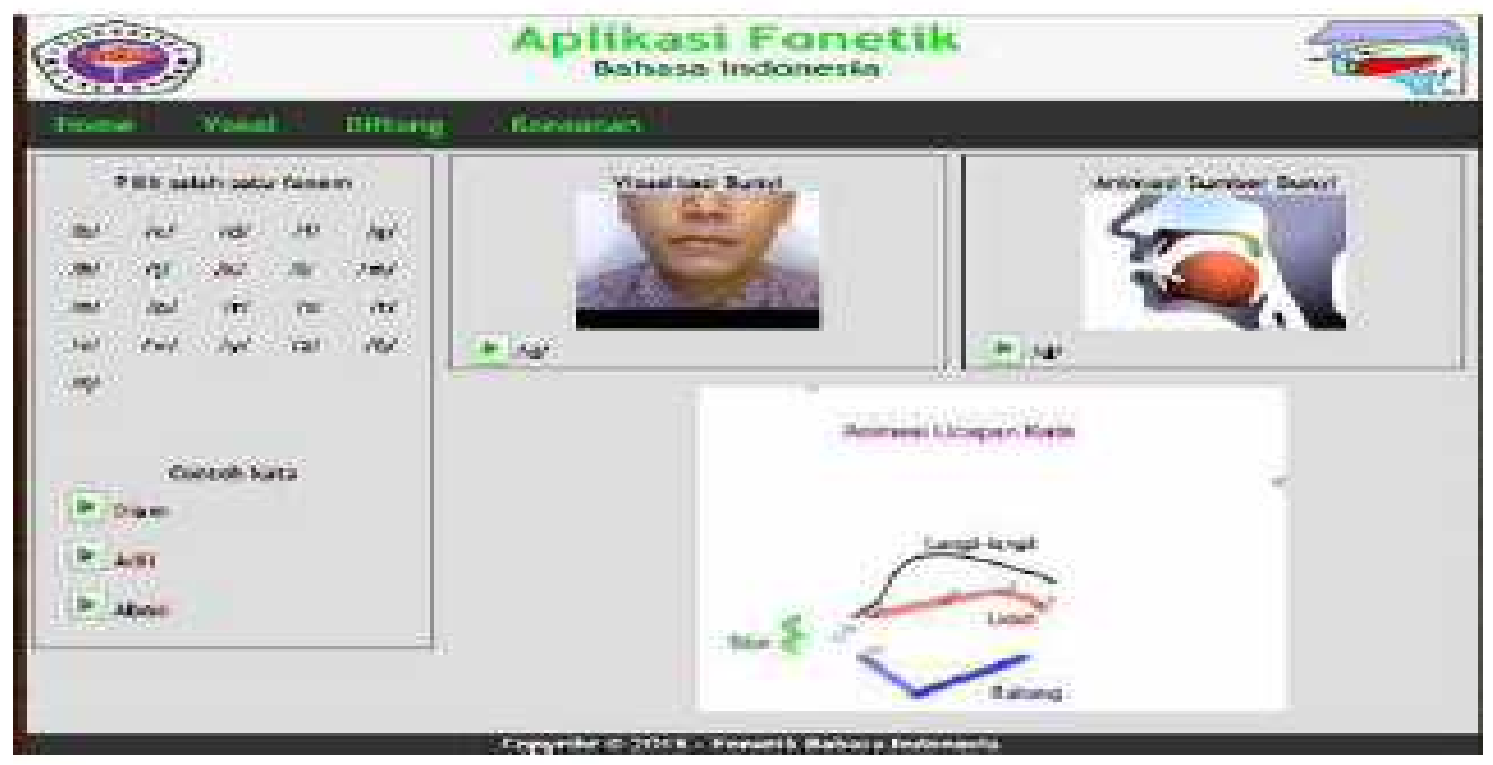

Page of consonants contains the lists of Indonesian consonants; they are b, c, d, f, g, h, j, k, l, m, n, p, r, s, t, v, w, $\mathrm{y}$, and $\mathrm{z}$. Users can find it by clicking 'consonants' which is in the menu bar. Then, when the lists of consonants are showed up, the user can choose one of the consonants. If one of the consonants is clicked, then it will display the page of sound visualization, sound source animation, and examples of the word. On the page of sound visualization and source sound animation, there is a 'play' button. Then if the user chooses one of the listed-words and clicks the 'play' button, it will show an animated word and played directly. Figure 3 displays the page of consonants.

Table 1. The Results of the Test of Black Box on Non-Native Speaker

\begin{tabular}{|c|c|c|c|c|}
\hline No. & Test & Input & Output expected & Description \\
\hline 1. & Home & $\begin{array}{l}\text { User chooses } \\
\text { "Home" }\end{array}$ & $\begin{array}{l}\text { Page view of vowels, diphthongs and } \\
\text { consonants }\end{array}$ & $\begin{array}{l}\text { Descriptions of vowels, diphthongs and } \\
\text { consonants with the pictures }\end{array}$ \\
\hline 2. & Vowels & $\begin{array}{l}\text { User chooses } \\
\text { "Vowels" }\end{array}$ & Page view of vowels & Vowels a, e, i, o, u and ə \\
\hline 3. & $\begin{array}{l}\text { Click one of the } \\
\text { vowels }\end{array}$ & $\begin{array}{l}\text { User chooses one } \\
\text { of the vowels }\end{array}$ & $\begin{array}{l}\text { Page view of vowels, sound } \\
\text { visualization, sound source animation, } \\
\text { examples of word and animated word }\end{array}$ & $\begin{array}{l}\text { Options of vowels, sound visualization, } \\
\text { sound source animation, examples of } \\
\text { words, and animated words }\end{array}$ \\
\hline 5. & $\begin{array}{l}\text { Click one of the } \\
\text { diphthongs }\end{array}$ & $\begin{array}{l}\text { User chooses one } \\
\text { of the diphthongs }\end{array}$ & $\begin{array}{l}\text { Page view of diphthongs, sound } \\
\text { visualization, sound source animation, } \\
\text { examples of word and animated word }\end{array}$ & $\begin{array}{l}\text { Options of diphthongs, sound } \\
\text { visualization, sound source animation, } \\
\text { examples of words, and animated words }\end{array}$ \\
\hline 6. & Consonants & $\begin{array}{l}\text { User chooses } \\
\text { "Consonants" }\end{array}$ & Page view of Consonants & $\begin{array}{l}\text { Consonants b, c, d, f, g, h, j, k, l, m, n, p, } \\
\text { r, s, t, v, w, y, z, ng, and ny }\end{array}$ \\
\hline
\end{tabular}

From all of the features that were tested according to the steps above, it can be concluded that the phonetic application (Visartico) (Ouni, 2012) has a valid value. To test the application, a questionnaire has been set up. The questionnaire was given to 30 respondents. The process begins with a demonstration of this Indonesian phonetic application, how to use it briefly and the explanation of how the program works, then the questionnaire distributed and every respondent gives their opinion on this application. 
Table 2. Questionnaire Result of Indonesian Phonetic Application

\begin{tabular}{llll}
\hline Questions & N & Mean & STDV \\
\hline Text can be read clearly and understandable & 30 & 24.3 & 21.22 \\
An appropriate of button placement in application & 30 & 26.0 & 27.05 \\
$\begin{array}{l}\text { Display on the overall application is easy to understand } \\
\text { Application has been running well }\end{array}$ & 30 & 26.6 & 30.5 \\
Is the application helpful in learning the Indonesian & 30 & 20.0 & 19.07 \\
phonetic articulation? & 30 & 27.6 & 36.4 \\
The application is easy to use or user friendly & 30 & 26.3 & 32.3 \\
Every button has been working well & 30 & 28.3 & 40.72 \\
Information displayed is clear & 30 & 27.6 & 38.65 \\
The application can minimize the time in gaining information & 30 & 27.0 & 32.44 \\
Is this application able to introduce Indonesian phonetic & & & \\
to many people & 30 & 29.0 & 15.1 \\
\hline
\end{tabular}

Based on the test result which is included in the criteria good (scale score $=40.4$ ) then it shows that respondents approved the application of Indonesian phonetic in terms of display, content, and function. This application is quite successful in enabling users in learning Indonesian phonetic, especially in learning the proper articulation.

\section{CONCLUSION}

The application that has been designed has given valid information about the function of phonetic and the activeness of vocal organs of native and non-native Indonesian. The animation that has been created based on vocal tract can be used to map the consonant sound which is often called as the sound of roaring which comes up in the sound spectrum. Yet it is too difficult to measure even using software such as audacity, SFS (Nagoor, 2010) or Praat (Boersma., \& Weenink. (2009). By using Praat, the information collected will only be in number or quantitative data. It cannot obtain an exact description where the location of sound vowel production and consonant which is spoken by native or nonnative languages. By using the application of Indonesian phonetic and vocal tract animation, it is expected to be known where the accurate position of the Indonesian native tongue when producing vocal and consonant sound as the reference for non-native speaker in learning the Indonesian speech sound.

\section{REFERENCES}

Boersma, P., \& Weenink, D. (2009). Praat: Doing phonetics by computer. (version 5.1.05).

Harrington, J., \& Cassidy, S. (1999). Techniques in Speech Acoustics. Kluwer Academic Publisher.

Naggor, K. (2010). Signals \& Systems. Tata McGraw Hill Education Private Limited.

Ouni, S. (2012). VisArtico: a visualization tool for articulary data. Annual Conference of the International Speech Communication Association InterSpeech. Portland.

Read, J. (2002). Innovation in Indonesian Language Teaching: an evaluation of the TIFL tertiary curriculum materials. Wollongong University.

van Zanten, E. (1989). The Indonesian Vowels, Acoustic and Perceptual Explorations. Dissertation. Leiden 